\title{
Professional Competence Is a Condition Precedent to Effective Management-An Argument for Practice Leaders in Legal Service Organizations
}

\author{
Manuel Jimenez \\ Correspondence: Manuel Jimenez, Adjunct Lecturer, College of Law Legal Studies Program, John F. Kennedy \\ University, United States.
}

Received: October 30, 2019

Accepted: December 4, 2019 Online Published: December 5, 2019

doi:10.11114/ijlpa.v2i2.4595

URL: https://doi.org/10.11114/ijlpa.v2i2.4595

\begin{abstract}
There is an unstated argument with an unsettling currency in today's organizations: Those that can't do, lead. The concept of management has devolved from a position that facilitates productivity and navigates workplace challenges, to a type of "bullshit job." To adherents of this philosophy, competence in one's vocation, profession or business is unnecessary in order to excel as a manager in that vocation, profession or business.

In professional environments technical competence in one's occupation is a condition precedent to good management. Technically competent managers come to positions of leadership with occupational gravitas. Occupational gravitas is forged from experience and imbues those who possess it with the confidence to effectively navigate the challenges confronting their organization. It is earned from experience dealing with the particular challenges of one's occupation.

Leadership skills are an adjunct to the occupational competence necessary for good management in professional environments. The concept that leadership skills are separate and apart from occupational competence, rather than ancillary to it, in the execution of good management is herein explicitly rejected.

People placed in positions of authority who lack experience, or are otherwise incompetent, bring with them not gravitas, but fear. Fear is the primary element from which springs management failures, and through which such failures are expressed. Incompetent leadership is not only dangerous to legal service provider organizations and their employees, but also exposes clients to dire consequences. In a legal services environment, bad management really is a public protection issue.

The model of a "practice leader," is the paradigm through which legal service organizations can model their management style. A practice leader is both an accomplished attorney as well as a leader. Practice leaders understand the work and the environment in which it is produced. This is important because it is they and the organization that are ultimately responsible for the work of their subordinates. Failure of leadership in a legal service environment can not only lead to litigation but could also lead to professional discipline when subordinates engage in misconduct.
\end{abstract}

Keywords: legal ethics, practice leader, management

\section{Introduction}

A post on the Onion-esque Austin Brew Blog entitled, "Celebrating Diversity: Company Promotes First Openly Incompetent Manager to Vice President," pokes fun at management incompetence and identity politics. The headline is satire, but the situation in the workplace is not. "Ineptitude in managers is unfortunately common," according to Amy Gallo, writing in the Harvard Business Review (2016). There is plenty of literature about bad management and incompetent managers. Too much of it gives the prevailing narrative that bad managers, although endowed with the technical expertise of their vocation, profession or business, fail because they lack the soft, interpersonal, communication, and organizational skills necessary to be effective. There is insufficient commentary on the fact that technical competence in one's occupation is a necessary component of good management.

There is an unstated argument with an unsettling currency in today's organizations: Those that can't do, lead. To adherents of this philosophy competence in one's occupation is unnecessary in order to excel as a manager in that occupation. It has become fashionable for those who would rather not engage in the vulgarities of their occupation to position themselves as having a particular aptitude to lead others in doing the work they themselves find either difficult 
or objectionable. This population of occupationally apathetic, but ambitious people consider themselves to be members of a managerial class. This cadre of self-diagnosed natural managers come into their sinecures of authority without a fundamental leadership requirement - occupational gravitas. There are too many people in positions of responsibility who exercise authority but take no responsibility; who can give orders but cannot lead.

For law firms, the practice manager is the default leadership model. Firms either meet client needs and expectations or go out of business. Firms with leadership that allow incompetent legal services invite the discipline of the marketplace. But, what about other legal service providers? Government lawyers work in environments divorced from the realities of the marketplace. Yet, such lawyers deal with matters that can have profound impacts on individuals and society. For government organizations, competence in the delivery of legal services is a public protection issue. This paper argues that for such legal service organizations the management model of the "practice manager," is best able to fulfill organizational and stakeholder needs and serves to protect the public. Practice managers have the occupational gravitas to make timely decisions and judgment calls based on competencies they've forged from experience in their vocation, profession or business ("occupation").

\section{Management Is Not a "Bullshit Job."}

In her article, "How to Manage People Who Know More Than You," Katie Wolf described her first day as a manager. She wrote that as a "24 year old former cupcake baker and technological spaz," she was hired by a software company to manage a team of people who all had years of experience (Wolf, 2013). She argued that to be successful in such a situation, one must: (1) be honest about your incompetence, (2) learn how to do your job from your subordinates, (3) get feedback from subordinates telling you how you should successfully do your job, and lastly, (4) respect your subordinates knowledge, so they'll be more receptive to your "leadership" (Wolf, 2013). The article not only highlights the fact that the author was totally unqualified for a management position, but calls into question the management of the company that would allow this situation to develop in the first place. It suggests a broader problem about how the concept of management has devolved from a position of leadership that facilitates productivity and navigates workplace challenges, to a type of "bullshit job."

David Graeber, in his work Bullshit Jobs: A Theory, describes certain types of managers as holding "bullshit jobs," which he divides into two subcategories: (1) Type 1, whose function is to assign work to others, and (2) Type 2, whose function is to create bullshit tasks for others to do (Graeber, 2018). Graeber writes that the former is useless but benign, while the latter is both useless and damaging (2018). Having a manager with a bullshit job forcing otherwise productive people to engage in bullshit work is counterproductive. Leadership divorced from the work of the firm engage in a type of busy-work that stifles productivity with counterproductive protocols and processes. A leader who is unable or unwilling to grasp the mechanics and tactical applicability of the work will be unable to understand the strategy into which it fits, nor realize the strategic importance for which it is performed.

The notion that competence in one's occupation is unnecessary to effectively manage is proffered by those advocating for the proposition that "management" is a vocation unto itself, separate and apart from the practicalities of one's occupation. It goes something like this: “Just because someone is a good [insert occupation description], doesn't mean they'll be a good manager." One may accept the proposition, which is fundamentally just a variation of the Peter Principle: "In a hierarchy every employee tends to rise to his level of incompetence" (Peter \& Hull, 1970). But, the truism itself is not the intended message of the statement. The intended message actually violates The Peter Principle and embraces The Dilbert Principle: "Leadership is nature's way of removing morons from the productive flow" (Adams, 1995). Left unsaid, but what the recipient is supposed to extrapolate, is that competence in one's occupation is not necessary to managing people who are so competent. Simply put, "One does not need to be competent to be a manager." The proposition is left unsaid because to state the proposition out loud is to expose it for what it is balderdash. This is particularly true when managing a highly educated, professional workforce. Academic management theories and de jure business leadership trends divorced from business practicalities doom their practitioners to failure.

\section{For Professional Service Providers, Occupational Competence is the Foundational Characteristic of Good Managers}

For the purpose of documenting that which should be obvious, this paper argues that in professional environments technical competence in one's occupation is a condition precedent to good management. Leadership skills are an adjunct to occupational competence. Simply being ambitious is not synonymous with being a competent manager. The concept that leadership skills are separate and apart from occupational competence, rather than ancillary to it, in the execution of good management is herein explicitly rejected. One of the core competencies, if not the primary competency of good management in a knowledge-based industry is occupational acumen.

Technically competent managers come to positions of leadership with occupational gravitas. Occupational gravitas is forged from experience and imbues those who possess it with the confidence to effectively navigate the challenges 
confronting their organization. It is earned from experience dealing with the particular challenges of one's occupation. Occupational gravitas is the judgment and fortitude needed to make difficult and timely decisions. People placed in positions of authority who lack experience, or are otherwise incompetent, bring with them not gravitas, but fear. Fear is the primary element from which springs management failures, and through which such failures are expressed.

\subsection{Managing Professionals Differs From Managing Other Types of Employees}

In his piece, "5 Ground Rules for Managing Professionals," Jo Owen argues that managing professionals differs from traditional notions of management because professionals are smart, educated, have little respect for managers, and don't like to be managed (Owen, 2009). Owen concludes, in part, that managing professionals is most effective when managers facilitate productivity by managing less: "Shield the professionals from all the corporate garbage that swills around -- adminstrivia, endless and pointless meetings, insane initiatives, relentless reporting and all the other stuff that organizations create with the sole intent of demoralizing everyone." The notion that managing professionals is difficult is not new. Joseph A. Roelin wrote in 1989 that documentation going back 30 years at that time demonstrated that professionals are more difficult to manage than nonprofessionals (Roelin, 1989).

In professional environments, select managers from the ranks of the professional staff who have demonstrated excellence in their professional capacity. They understand the mechanics of their profession and know the resources necessary to accomplish objectives. In legal service environments, professionals are in the best position to exercise good judgment and make decisions regarding work at the line level. Failing to enfranchise professionals with the authority to exercise judgment and control their work is counterproductive. Knowing where to draw the line between decisions rightfully reserved for management and those best left to professionals, comes from leaders who are experienced in both their administrative role and the underlying occupation.

Earning the trust of a professional workforce is important to managing them in a legal services environment. To be successful, practice leaders must have earned the respect of their professional colleagues with a demonstrated history of professional competence (Maister, 1993). "The best managers earn respect through performance. Not only do they drive business results, but they serve as mentors and sponsors who help teach others how to do the same. High-performance managers get their hands dirty and are not afraid of rolling up their sleeves. They get in the game and remain active they stay in it to win it" (Llopis, 2013).

My own research indicates that professionals are more likely than other workers to view a manager's competence as a factor when making determinations about whether a manager is successful or not. Professionals are more likely to report having worked with poor managers over the course of their work lives; are twice as likely as non-professionals to identify incompetence as a factor in bad management; more likely to identify such managers as being unqualified in their occupation; as well as perceiving them to be incapable of giving substantive guidance to subordinates. In a survey conducted from April 8, 2018 through May 4, 2018, (N=203), seventy-nine percent (79\%) of the non-professional workers surveyed reported having worked with a bad manager over the course of their working lives, but only twenty-one percent $(21 \%)$ of that population reported that incompetence was a factor that made the manager bad. Professionals who were surveyed, on the other hand, were more likely to identify having worked with a bad manager, and more likely to cite competency as an issue contributing to bad management. Eighty-nine percent (89\%) reported having worked with a bad manager over the course of their work lives. Forty-one percent (41\%) of that population identified incompetence as a factor contributing to their determination that a manager is bad. Professionals also perceived more micromanagement from bad managers than did non-professionals, twenty-eight percent (28\%) versus nineteen percent (19\%), and were twice as likely to identify bad managers as being indecisive - unable or unwilling to make decisions - twenty-one percent (21\%) versus ten percent (10\%).

\subsection{The Practice Leader}

The model of a "practice leader," as articulated by David H. Maister in his work, "Managing the Professional Service Firm," provides a paradigm through which legal service organizations should begin to design their organization's management style (Maister, 1993). A practice leader is both an accomplished attorney as well as a leader. A practice leader should be accomplished at his profession to the extent that they are able to (1) differentiate between that which is important from what is not, (2) make timely and informed decisions and judgment calls, (3) delegate decisions to those in the best position to make particular decisions, and (4) serve as a professional resource to guide professionals toward quality, productivity and efficiency.

As a practical matter, following the practice leader model benefits the legal service organization. Practice leaders understand both the work and the environment in which it is produced. This is important because it is the organization and its leadership that are ultimately responsible for the work of subordinates. 


\section{Fear Based Management}

Fear explains management behaviors which otherwise do not make sense. Those that strive to be in positions of leadership are often the exact types of people who should not exercise authority. Self-preservation is the goal for which fearful managers strive. For those that find their occupation difficult, one of the best ways to escape it is to be kicked upstairs. People in positions of authority who lack occupational gravitas are not leaders, but administrators. Once in positions of leadership, another type of fear seeps into their psyche - fear of being exposed by subordinates as a fraud. And thus, fearful managers build up defensive structures to protect themselves. Counterproductive management measures can invariably be explained by fear, including the love of procedure and protocols that stifle productivity, an inability to make timely decisions, and reliance on decision making mechanisms that delegate or dilute responsibility.

\subsection{Fearful Managers}

As the modern workplace changes and the nature of work evolves, remunerative valuation of so called "work" increasingly bears less and less relation to its proximity to the utility of said work. In "Bullshit Jobs," Graeber suggests that there may be an inverse relationship between the social value of work and compensation (Graeber, 2018, p. 147). The more abstract the relationship between one's employment from productivity, the higher the compensation. Employment based on overly complicated theoretical constructions utilizing polysyllabic jargon to engage in faux work can be some of the best paid positions in the American workforce. For instance, a brief search of a major online employment search engine of jobs paying more than $\$ 110,000$ a year included the following position titles: Leader for Enterprise Diversity, Inclusion \& Volunteerism, Talent Mobility Program Manager, Head of People, Job Architect, People Operations Strategy and Communications, and People and Change Consultant - Manager.

This appears to be a result of people leaving college, entering the workforce and coming to realize, "Hey! This work thing sucks." Real work is hard. With a growing constituency of educated people entering the workforce using soft-skills and social networking to land jobs for which they are both unqualified and overcompensated, there appears to be an evolving culture of contempt for productive work. Thus, occupations based on silly trends and magical thinking flourish. As Nathan Heller writes, "[B]ullshit employment has come to serve in places like the U.S. and Britain as a disguised, half-baked version of the dole -- one attuned especially to a large, credentialled middle class" (2018). This form of bourgeois welfare is inappropriate in organizations that provide legal services. Those escaping work by clawing their way into management are dangerous to the organization, its employees, and its constituents.

\subsection{Do Something! That's Your Job}

Lead, follow, or get out of the way. Leaders make decisions. That's their job. Bad managers avoid making decisions and refuse to take responsibility for decisions, all the while attempting to maintain control of the decision-making process. In her work, "Ten Habits of Incompetent Managers," Margaret Heffernan wrote that bad managers have a bias against action: "There are always reasons not to make a decision, reasons to wait for more information, more options, more opinions. But real leaders display a consistent bias for action. People who don't make mistakes generally don't make anything" (Heffernan, 2016).

Delaying or failing to make necessary decisions, or preventing others from making decisions, stops productivity. This is true regardless of the expression of the indecision: Delegating decision making to subordinates; requiring excessive information before making decisions; creating cumbersome protocols in the decision-making process wherein managers retain authority pollice verso ${ }^{l}$ while delegating responsibility; or subjecting all decision making to a process of collaboration or consensus. If you can't make decisions, you're not a leader and you should get out of the leadership business.

\subsection{Prioritizing Protocol Over Productivity, and Process Over Progress}

Managers lacking occupational gravitas lack the experience to appreciate the time and resources required to do the jobs they charge others with doing, resulting in unrealistic timelines and expectations. Magnifying this deficit is the tendency of incompetent managers to exaggerate the probability of, and ramifications from, possible mistakes. Thus, they create roadblocks to productivity by prioritizing protocol over productivity, and process over progress. "Rules and processes exist to expedite business, not ritualize it. Love of procedure often masks a fatal inability to prioritize" (Heffernan, 2016). Efforts to maintain control result in rigid protocols which are maladaptive in changing environments or when challenges present themselves. "Full-time managers, whose raison d'etre is managing, are...more likely to reduce autonomy and to increase bureaucracy and structure. These actions create rigidities that make it difficult to respond to client needs and market changes and therefore demotivate professionals" (Mathias \& Lorsch, 2014).

\footnotetext{
${ }^{1}$ Latin: Roughly translates to "with a turned thumb."
} 


\section{You Can Delegate Authority, But Not Responsibility}

Bad managers delegate responsibility for making decisions, while maintaining control. This is a sort of insidious burden shifting by which bad managers utilize a decision-making apparatus more associated with La Cosa Nostra ${ }^{2}$ than good leadership. This takes several forms. Yegor Loginov observes in his piece, "Seven Signs of Incompetent Managers," managers who lack professional skill may delegate decisions to subordinates (2017). When something goes south, incompetent managers shift responsibility to the subordinates to whom they've improperly delegated their responsibilities (Loginov, 2017).

Another form of decision delegating is the outsourcing of decision making, such as using outside consultants, which is time consuming and an expensive way to avoid having to make decisions (Heffernan, 2016). Consultants are outsiders with limited knowledge of an organization. This wastes time, costs money, and leads to uninformed conclusions disguised as expert opinions.

While delegating decision-making to others serves as a mechanism to avoid having to make decisions, decision making by committee or consensus is a mechanism to dilute accountability for decisions-making amongst a group of people, which implicates another indicia of bad management - addiction to meetings. "There are many ways to foster a successful company, but being addicted to meetings just for the sake of it isn't one of them...It's a sign of poor time management and a symptom of a manager who's using fluff to make it seem like something important is happening" (Alton, 2014). Bad managers "are drawn to meetings like moths to a porch light" (Adams, 1995). Consensus decision making slows down the decision-making process, resulting in decisions not being timely made and, thus, stifling productivity. More importantly, with the dilution of accountability, managers are not held accountable for bad decisions, which is exactly the purpose of the process.

\section{The Practice Leader in Legal Services Organizations}

Legal service providers that allow poor management practices and bad managers to thrive are a threat to themselves and their constituents. Legal services environments employ a highly educated, sophisticated workforce to produce complex work. The work can have serious ramifications for the organization, clients and other stakeholders. Incompetent leadership is not only dangerous to legal service provider organizations and their employees, but also can expose clients to negative consequences. In a legal services environment, bad management really is a public protection issue.

Every state in the United States has a rule of professional conduct that requires attorneys to provide competent representation to clients. Attorneys can be disciplined, including being disbarred for misconduct based on their failure to perform with competence. Furthermore, attorneys who supervise the work of others can be disciplined for the misconduct of their subordinates.

Courts around the country have held that attorneys can be disciplined for the professional misconduct of subordinates. The Supreme Court of California has held that an attorney is responsible for the work product of employees performed pursuant to his direction and authority (Crane v. State Bar, 1981). In Gadda v. State Bar, the Supreme Court of California rejected the contention that a supervising attorney is only as responsible as the subordinate who committed professional misconduct, reasoning that the duty of supervision is separate and distinct from the underlying duty to act competently (Gadda v. State Bar, 1990). The New Jersey Supreme Court issued a decision that went beyond the misconduct of an attorney and spoke about a law firm's responsibility to supervise (Matter of Ritger, 1989). The Court wrote:

$[R]$ espondent, a trial lawyer of thirty-eight years' experience, was coping with a heavy, active trial calendar during much of the time that the events involved in these proceedings were pressing in on him...For today's purposes it is sufficient that we express our sense of unease over the extent to which the supervising firm carried out its end of the arrangement. The occasion affords us the opportunity to remind the bar that when lawyers take on the significant burdens of overseeing the work of other lawyers, more is required than that the supervisor simply be "available."

According to the American Bar Association, lawyers with leadership responsibilities must make reasonable efforts to ensure that their subordinates comply with ethical rules, including the rule requiring competent representation (American Bar Association [ABA], Center for Professional Responsibility, 2018). It is hard to imagine how a leader in a legal services organization can ensure their subordinates perform competently if they themselves are not accomplished in their own profession.

\footnotetext{
${ }^{2}$ Loosely translated from Italian as "This thing of ours," or "our thing." The phrase is popularly associated with being a self-referential label of Italian-based crime syndicates.
} 


\section{Conclusion}

Successful leaders make decisions. That is their job. Decisions precede action. Action facilitates productivity. When a decision is needed, doing something is almost universally better than doing nothing. Doing something in a situation where doing nothing is detrimental is not an act of courage. Failing to do anything, on the other hand, looks a lot like cowardice. Those in positions of authority who cannot, or otherwise will not make timely decisions, are bad managers.

Legal service organizations act in their own best interests when they fill organizational leadership roles with practice leaders, i.e. accomplished lawyers serving as leaders. Such leaders are knowledgeable about the work of the organization and the environment in which it is produced. Such leaders come with occupational gravitas, forged from experience, and imbued with the confidence to effectively navigate the challenges confronting their organization. It is earned from experience dealing with the particular challenges of one's occupation.

When occupational gravitas is missing, organizations are hobbled by fearful managers unable to differentiate between what is important and what is trivial. In times of transition and change, where timely decisions are required, based on informed judgement, managers without professional gravitas are unable to make timely judgment calls. They also prevent others from making necessary decisions, are unable to triage, and are ultimately unable to effectively manage and thus the bad manager is born. Once born, bad management never dies. "[T]he sad fact of the matter is that incompetence, among the upper strata of many organizations, often goes unpunished. Actually, a good percentage of the time, it's rewarded" (Becker, 2015).

\section{Acknowledgements}

The author would like to acknowledge the contributions of Timothy-Scott Kim Jimenez who volunteered as a research assistant and helped design the survey, "Prevalence of Contra-Indicated Management Characteristics in the Workplace," and both Bo-Kyung Kim, JD, LL.M. and Laura Huggins, JD, for their review and editorial assistance of this paper.

\section{References}

Adams, S. (1995, February 5). Dilbert. Retrieved from http://dilbert.com/strip/1995-02-05

Alton, L. (2014). 5 signs of a bad manager. Retrieved from https://www.business.com/articles/5-signs-of-a-bad-manager/

American Bar Association, Center for Professional Responsibility. (2018). Model rules of professional conduct. Retrieved

from http:/www.americanbar.org/groups/professional_responsibility/publications/model_rules_of_professional_conduct/

Becker, S. (2015). What are employers really looking for? Incompetence. Retrieved from https://www.cheatsheet.com/money-career/what-are-employers-really-looking-for-incompetence.html/

Celebrating diversity: Company promotes first openly incompetent manager to vice president. (2017). Retrieved from http://austinbrewblog.com/wp_brewblog/2017/08/company-promotes-incompetent-manager/

Crane v. State Bar. 30 Cal.3d 117. Supreme Court of California. 1981.

Gadda v. State Bar. 50 Cal.3d 344. Supreme Court of California. 1990.

Gallo, A. (2011). Dealing with your incompetent boss. Harvard Business Review. Retrieved from https://hbr.org/2011/06/dealing-with-your-incompetent

Graeber, D. (2018). Bullshit jobs. New York: Simon \& Schuster.

Heffernan, M. (2016). Ten habits of incompetent managers. Fast Company. Retrieved from https://www.fastcompany.com/919287/ten-habits-incompetent-managers/

Heller, N. (2018). The bullshit-job boom. The New Yorker. Retrieved from https://www.newyorker.com/books/under-review/the-bullshit-job-boom/

Llopis, G. (2013). Effective managers earn trust quickly by doing 5 things well." Forbes Magazine. Retrieved from https://www.forbes.com/sites/glennllopis/2012/07/10/effective-managers-earn-trust-quickly-by-doing-5-things-wel $1 / \# 2 b 1 b c 48 c 5631$

Loginov, Y. (2014). Seven signs of incompetent managers. Retrieved from https://loyp.ru/en/vision/management/seven-signs-of-incompetent-managers.html

Maister, D. H. (1993). Managing the professional service firm. New York: Free Press Paperbacks.

Mathias, J. W., \& Lorsch, P. F. (2014). When professionals have to manage. Harvard Business Review. Retrieved from https://hbr.org/1987/07/when-professionals-have-to-manage 
Matter of Ritger. 115 N.J. 50. Supreme Court of New Jersey. 1989.

Owen, J. (2009). 5 ground rules for managing professionals. CBS News. Retrieved from https://www.cbsnews.com/news/5-ground-rules-for-managing-professionals/

Peter, L. J., \& Hull, R. (1970). The Peter principle. New York: Bantam.

Raelin, J. A. (1989). An anatomy of autonomy: Managing professionals. The Academy of Management Executive, 3(3), 216-228. https://doi.org/10.5465/ame.1989.4274740

Wolf, K. D. (2018). How to manage people who know more than you. Retrieved from https://www.themuse.com/advice/how-to-manage-people-who-know-more-than-you/

\section{Copyrights}

Copyright for this article is retained by the author(s), with first publication rights granted to the journal.

This is an open-access article distributed under the terms and conditions of the Creative Commons Attribution license which permits unrestricted use, distribution, and reproduction in any medium, provided the original work is properly cited. 